\title{
Prescribers Factors and Patients Socio- Demographic Factors Influencing Quality Care Management of Febrile Illnesses in Ghana.
}

\section{Asante Koranteng Samuel}

Kwame Nkrumah University of Science and Technology

Brenyah Joseph Kwasi ( $\square$ bresjosaf@gmail.com )

Kwame Nkrumah University of Science and Technology

Mensah Akohene Kofi

Kwame Nkrumah University of Science and Technology

Agyei -Baffour Peter

Kwame Nkrumah University of Science and Technology

Opoku Daniel

Kwame Nkrumah University of Science and Technology

Okyere Perditer

Kwame Nkrumah University of Science and Technology

\section{Research Article}

Keywords: Prescribers Factors, Patients Socio-demographic Factors, Influencing, Quality Care Management, Febrile Illnesses, Ghana.

Posted Date: March 2nd, 2021

DOl: https://doi.org/10.21203/rs.3.rs-253107/v1

License: (c) (i) This work is licensed under a Creative Commons Attribution 4.0 International License. Read Full License 


\title{
Prescribers Factors and Patients Socio-demographic Factors Influencing Quality Care Management of Febrile Illnesses in Ghana.
}

\section{Asante Koranteng Samuel ${ }^{1}$, Brenyah Joseph Kwasi ${ }^{2}$, Mensah Akohene Kofi ${ }^{3}$, Agyei - Baffour Peter, ${ }^{4}$ Opoku Daniel, ${ }^{5}$ Okyere Perditer ${ }^{6}$}

\author{
Authors Details: \\ ${ }^{1 *}$ Department of Health Policy, Management and Economics, School of Public Health, Kwame \\ Nkrumah University of Science and Technology, Ghana \\ ${ }^{2}$ Department of Global and International Health, School of Public Health, Kwame Nkrumah University \\ of Science and Technology, Ghana \\ ${ }^{3}$ Department of Health Policy, Management and Economics, School of Public Health, Kwame Nkrumah \\ University of Science and Technology, Ghana \\ ${ }^{4}$ Department of Health Policy, Management and Economics, School of Public Health, Kwame Nkrumah \\ University of Science and Technology, Ghana \\ ${ }^{5}$ Department of Health Policy, Management and Economics, School of Public Health, Kwame Nkrumah \\ University of Science and Technology, Ghana \\ ${ }^{6}$ Department of Medicine, School of Medicine and Dentistry, Kwame Nkrumah University of Science \\ and Technology, Ghana
}

\begin{abstract}
Introduction

Febrile illnesses in children and its management (especially infectious diseases) continue to result in an enormous increase in morbidity and mortality in developing countries causing a global public health concern. However, most low-middle-income countries have failed to institute systematic outcome assessment measures to ensure quality in the management of these conditions at one breadth. This study therefore aimed at assessing the quality care management of febrile illness in under five (5) in health facilities in the Atwima Kwanwoma district of Ashanti Region, Ghana.
\end{abstract}

\section{Methods}

\footnotetext{
$1 *$ Brenyah Joseph Kwasi is the corresponding Author. All Correspondences should be directed to Email: bresjosaf@gmail.com / jkbrenyah@ @nust.edu.gh and contact number is +23324527746
}

To cite this article: Asante, K, S., Brenyah, J. K., Mensah, A, K., Agyei-Baffour, P., Opoku, D., Okyere, P. (2021). Prescribers Factors and Patients Socio-demographic Factors Influencing Quality Care Management of Febrile Illnesses in Ghana. 
The study was quantitative using a cross-sectional study design. Data were collected from 58 healthcare providers and 390 folders of children treated for febrile illnesses. Data were analyzed using STATA version 14. Univariate and multivariate analyses were performed to identify socio-demographic, patient and prescribers' factors influencing management of febrile illness among children under 5 years. Statistical significance for all testing was set as 0.05.

\section{Results}

The mean age and standard deviation of the prescribers were $30.2 \pm 3.4$. Majority of the prescribers $(65.5 \%)$ were aged between 23 -30years and the rest (34.5\%) between 31-37years. About $67.3 \%$ were females and the rest $(32.7 \%)$ were males, more than half of the prescribers $(70.7 \%)$ were married and the rest $(29.3 \%)$ were single. More than half $(55.6 \%)$ of patients seen were females and $44.4 \%$ were males. Most of the patients $(43.8 \%)$ who presented with febrile illnesses were between 0-11 months, while $29.1 \%$ and $27.2 \%$ of them were between 1 2 years and 3-5 years respectively. The average age of children was 5.7 \pm 2.3 months for those who were less than a year and 2.8 \pm 1.4 years for those between 1-5years. Patients who believed in superstition were less likely to receive quality care management of febrile illness as compared with those who did not believe in superstitions ( $\mathrm{AOR}=0.50 ; 95 \% \mathrm{CI}=0.03-0.70)$. The results depict that socio-demographic factors such as age of a child and gender, influenced quality care management of febrile illness as detailed in Table 4. For instance, children below 1 year were less likely to receive quality care management of febrile illness as compared with those above 3 years $(\mathrm{AOR}=0.05 ; 95 \% \mathrm{CI}=0.08-0.28)$. Also, female children were more likely to receive quality care management of febrile illness as compared with their male counterparts $(\mathrm{AOR}=1.50 ; 95 \% \mathrm{CI}=0.03-0.70)$.

\section{Conclusion}

The study concludes that, prescribers' factors such as those who believed in superstition and socio-demographic factors of children such as age and gender influenced quality care management of febrile illness.

\section{Recommendations}

Health policy makers should promote health education to reduce the negative effects of supersitition in health care management.

Key Words: Prescribers Factors, Patients Socio-demographic Factors, Influencing,

Quality Care Management, Febrile Illnesses, Ghana.

\section{Background of the study}

Reducation of childhood diseases has been a growing concern of health professionals and policy makers for some decades now. Research outcomes have revealed that, febrile illnesses account for one of the causes of global infant morbidity and mortality[1,2]. It is one of the most common and single reasons why children under five seek both emergency and primary care in facilities $[3,4]$. Febrile illness include malaria, measles, pneumonia, diarrhea and tuberculosis $[5,6]$. On average a child experiences an episode of febrile illnesses every year [2] and the need for continuous quality management of such conditions cannot be ignored. Quality management in healthcare encompasses the application and management of medical science and technology in a manner which maximizes its benefits to health delivery without correspondingly increasing $\operatorname{risk}[7,8,9]$. 
Being regarded as the main contributor to infant deaths in sub-Saharan Africa, febrile illness remains a major public health concern $[10,11,6]$. Black et al. [10], estimated that febrile illness causes about $68 \%$ of all infant deaths in Africa with malaria being the leading cause of death in children under 5 years. For instance out of the estimated global 6.6 million children under5 mortaility in 2012, estimated $82 \%$ was attributed to sub-Saharan Africa and Southern Asia while pneumonia, diarrhea and malaria accounted for $17 \%, 9 \%$ and $7 \%$ respectively [12].

Due to the alarming nature of these diseases, effective medicines and control strategies to reduce its prevalence have been initiated in Africa. The WHO together with other stakeholders have made efforts for the effective management of this fever-related conditions $[13,14]$. However, not much has been achieved, as the impact of these interventions in the sub-Sahara is typically low. The failure of attempts to eliminate these diseases has been attributed to prescriber's skills, efforts and patients factors. Davey, [15] found out that, factors derailing the achievement of quality management of febrile conditions are lack of funding to implement interventions, poor governments' commitment, poor health service systems, effects of rapid improvement standards visa-vis the slow learning pace of health care profesionals. It is clear that, the prescribers and patients socio-demographic factors influencing quality care management of febrile illnesses were missed out in that study.

However, this gap was noted and a study conducted by Mosadeghrad, (16) reported that, patients' socio-demographic factors and prescriber factors such as severity of illness, socioeconomic status, cost of health care, gender, superstition, fear of lack of Confidentiality of patients' records, low participation in health insurance, geography, proximity to the hospital affect the outcomes of quality care management of febrile conditions. It is therefore important to initiate a study of this nature in Ghana to ascertain any variations in how prescriber factors and patients socio-demographic factors influence quality care Management of fibrile illness in children under 5 .

\section{Methodology}

\section{Study type and design}

A cross-sectional study design was used with the aim of examining the quality care management of febrile illness in Ghana using quantitative approach.

\section{Study population}

The study population involved all prescribers in the Foase sub-district and also children under five (5) years with febrile illnesses who were seen in the health facilities. A total of 23 health facilities were involved in this study.

\section{Inclusion and Exclusion Criteria}

The inclusion criteria involved all prescribers (doctors, physician assistants, and nurse prescribers) in the health facilities who have served in the district for at least three (3) months. Again, medical records /folders of children under 5 years presented with temperature $\geq 38.0$ ${ }^{\circ} \mathrm{C}$ and were diagnosed and treated for febrile illness were used for the study. The exclusions involved medical records / folders of children above 5years, presented with temperature $<38.0$ ${ }^{\circ} \mathrm{C}$. Again, children who were diagnosed and treated of febrile illness in the health facilities outside the stipulated research duration were also excluded. Moreover, prescribers who have served in the facilities less than 3 months were excluded. 


\section{Sample Size and Sampling Method}

The sample size for the children was calculated using the $64 \%$ prevalence of febrile illnesses (the majority being malaria) in children under five (5) years in Ghana (Owusu-Agyei et al., 2009). With this prevalence, the sample size was calculated using Cochrane sample size formula. Where $n=$ the desire sample size, $p=0.64$ proportion of children with febrile illness and $d=0.05$ desire precision. An initial sample size of 354 was estimated and an assumed nonresponse rate of $10 \%$ was factored in arriving at a final sample size of 389 . Also, a total of 58 prescribers (representing all prescribers) within the five health facilities used for the study. These included; 2 medical officers, 13 physician assistants, and 43 nurse prescribers (18 midwives and 25 nurses).

\section{Sampling Method}

A simple random sampling method was used to select the sample of medical records of the children who visited the five health facilities. A population proportion to the size of the children under five within the sub-district was used to estimate the number of folders to be selected from each facility. We therefore used the number of folders seen during the study period in facility divided by the total number of folders seen in all the facilities and further multiply by the calculated sample size. A simple random sampling method was used to select the folders based on our inclusion criteria once the sample for each facility was determined.

A random list of serial numbers was then generated using Research Randomizer online [17]. For instance, at Aburaso Methodist Hospital, all folders within the study period were numbered serially. In this case, the estimated proportion of 248 was entered into the software, a random list of serial numbers totalling 248 was automatically generated. The number of folders bearing the corresponding serial numbers were retrieved and included in the study. This process was repeated in all the other facilities until the required sample size was attained. A purposive sampling method based on work experiences, number of years served, specialty, and among others was used to select the 58 health care prescribers

\section{Data collection Technique and tools}

Two types of data were collected; primary and secondary data. The primary data were collected using a structured questionnaire programmed and loaded onto a smartphone. The smartphone was running with installed Open Data Kit software designed for Android. The questionnaire was administered by trained research assistants and collected data uploaded to a cloud-based server for safekeeping and aggregation. The questionnaire was grouped into sections. Data collected included socio-demographic characteristics of the respondents, prescribers' factors believed to be influencing quality care management. The questionnaires were drafted, pretested, amended and administered in English. The secondary data was extracted from patient records at each of the sampled facilities in the study area based on the indicators sought from the patients bio-data.

\section{Data analysis}

The data was cleaned, entered and analyzed using Stata Version 14. The descriptive data were presented using frequencies with their corresponding percentages, tables, and charts where necessary. Univariate and multivariate analyses were performed to identify patients' sociodemographic factors and precribers' factors influencing management of febrile illness among children under 5 years. Statistical significance for all testing was set as 0.05 . 


\section{Ethical Consideration}

All the study protocols were submitted to Committee on Human Research Publication and Ethics of the School of Medical Sciences, Kwame Nkrumah University of Science \& Technology, Kumasi for review and clearance. Permission for the collection of the data was sought from the office of the District Health Directorate, the Medical Suprintendents of the respective hospitals and Heads of Departments of the Outpatients Department (OPD). The purpose of the research was explained to prescribers and officers' in-charge of medical records at the various facilities in order to have access to the data. The privacy of respondents was strictly observed as much as possible. All the research ethical principles were maintained to the latter during the conduct of this study.

\section{Consent to Participate}

All the participant consented to participate after the purposes of the research was explained to them. Again, all human subjects were provided with written informed consent to participate. The participants were also given the righ to opt out in the course of the interview without any threat. The whole interview process was conducted in a friendly and interactions between the interviewer and interviewees were smooth.

\section{RESULTS}

\section{Sociodemographic Characteristics of Prescribers}

The detailed results of the background characteristics of prescribers included in this study are presented in Table 1. The mean age and standard deviation of the prescribers were 30.2 \pm 3.4 . Majority of the prescribers $(65.5 \%)$ were aged between $23-30$ years and the rest $(34.5 \%)$ between 31-37years. About $67.3 \%$ were females and the rest $(32.7 \%)$ were males. Again, more than half of the prescribers $(70.7 \%)$ were married. The majority of the prescribers $(62.1 \%)$ had a Diploma as the highest educational qualification while the rest $(37.9 \%)$ had first degree. Most of the professionals (43.1\%) were Nurse Prescribers followed by midwives (31.0\%), Medical/Physician Assistants (22.4\%) and medical officers (3.5\%).

According to the ranks of the prescribers, about $43.1 \%$ were nurse prescribers and the least number of prescribers were junior medical officers $(1.7 \%)$ and senior medical officers $(1.7 \%)$. The prescribers had been in their various professions for an average of $4 \pm 2.8$ years. Majority of prescribers $(62.1 \%)$ had been working in their profession not less than 5years. On the average the prescribers had $4 \pm 3$.1years as practice years of experience. More than half $(53.5 \%)$ of the prescribers work five days a week, while a few also work throughout the week $(1.7 \%)$. On average, $3.8 \pm 2.2$ cases of febrile illnesses are seen every day, however majority $(87.9 \%)$ of the prescribers stated that they see between 1-5 cases every day.

\section{Table 1: Demographic Characteristics of Prescribers}

\begin{tabular}{|l|l|l|}
\hline Characteristics & \multicolumn{1}{|c|}{$\boldsymbol{n = 5 6}$} & $\mathbf{\%}$ \\
\hline Age group 23-30years & & \\
\hline \multicolumn{1}{|c|}{ 31-37 years } & 38 & 65.5 \\
\hline Mean (SD) & 20 & 34.5 \\
\hline
\end{tabular}




\begin{tabular}{|c|c|c|}
\hline Sex & & \\
\hline Male & 19 & 32.7 \\
\hline Female & 39 & 67.3 \\
\hline \multicolumn{3}{|l|}{ Marital status } \\
\hline Single & 17 & 29.3 \\
\hline Married & 41 & 70.7 \\
\hline \multicolumn{3}{|l|}{ Educational level } \\
\hline Diploma & 36 & 62.1 \\
\hline First degree** & 22 & 37.9 \\
\hline \multicolumn{3}{|l|}{ Principal profession } \\
\hline Medical Officer & 2 & 3.5 \\
\hline Medical/Physician Assistant & 13 & 22.4 \\
\hline Midwife & 18 & 31.0 \\
\hline Nurse prescriber & 25 & 43.1 \\
\hline \multicolumn{3}{|l|}{ Rank at Facility } \\
\hline Senior Medical Officer & 1 & 1.7 \\
\hline Junior medical officer & 1 & 1.7 \\
\hline Senior Medical/Physician Assistant & 2 & 3.5 \\
\hline Medical/Physician Assistant & 12 & 20.7 \\
\hline Midwife & 10 & 17.2 \\
\hline Nurse prescriber & 25 & 43.1 \\
\hline Senior midwife & 7 & 12.1 \\
\hline \multicolumn{3}{|l|}{ Working experience at Profession (Years) } \\
\hline $1-11$ months & 7 & 12.1 \\
\hline $1-5$ years & 36 & 62.1 \\
\hline 6 years and above & 15 & 25.8 \\
\hline Mean SD & $4.04(2.8)$ & \\
\hline \multicolumn{3}{|l|}{ Working experience at Facility (Years) } \\
\hline $1-11$ months & 5 & 8.9 \\
\hline 1-5years & 35 & 62.5 \\
\hline 6 years above & 16 & 28.6 \\
\hline Mean SD & $4.3(3.1)$ & \\
\hline \multicolumn{3}{|l|}{ Number of febrile illness seen daily } \\
\hline $1-5$ cases & 51 & 87.9 \\
\hline $6-10$ cases & 7 & 12.1 \\
\hline Average cases seen daily (SD) & $3.8(2.2)$ & \\
\hline
\end{tabular}

** First degree: Includes University and Postgraduate

*Data was presented in absolute figures with corresponding percentages

Source: Authors Survey, 2020

\section{Socio-Demographic Characteristics of Patients}

More than half $(55.6 \%)$ of patients seen were females and $44.4 \%$ were males. Most of the patients $(43.8 \%)$ who presented with febrile illnesses were between $0-11$ months, while $29.1 \%$ and $27.2 \%$ of them were between 1-2 years and 3-5 years respectively. The average age of children was $5.7 \pm 2.3$ months for those who were less than a year and $2.8 \pm 1.4$ years for those between 1-5years. Majority of the patient's folder (79.2\%) were from Aburaso Methodist Hospital with the least being from Dufie memorial clinic (1.9\%). Medical assistants (33.6\%) dominated the ranks of prescribers who saw the cases used for this study. 
Table 2: Demographic Characteristics of Patients

\begin{tabular}{|l|l|l|}
\hline Variables & $\boldsymbol{n}=\mathbf{3 1 3}$ & $\mathbf{\%}$ \\
\hline Sex of children & & \\
\hline Male & 139 & 44.4 \\
\hline Female & 174 & 55.6 \\
\hline Age & & \\
\hline 0-11 months & 137 & 43.8 \\
\hline 1-2 years & 91 & 29.1 \\
\hline 3-5 years & 85 & 27.2 \\
\hline Mean age in months (SD) (n=137) & $5.7(2.3)$ & \\
\hline Mean age in years (SD) $(\boldsymbol{n = 1 7 6})$ & $2.8(1.4)$ & \\
\hline Facility patients are seen & & \\
\hline Millennium Hospital & 16 & 5.1 \\
\hline Trinity Hospital & 22 & 7.0 \\
\hline Aburaso Methodist Hospital & 248 & 79.2 \\
\hline Foase Health Center & 21 & 6.7 \\
\hline Dufie Memorial Clinic & 6 & 1.9 \\
\hline
\end{tabular}

Source: Authors' Survey, 2020

\section{Prescribers' Factors Influencing Quality Care Management of Febrile Illnesses}

Table 3 describes prescribers' factors influencing quality care management of febrile illness as perceived by prescribers. Cost of healthcare $(88.9 \%)$ and socio-economic status of patients $(90.7 \%)$ were believed by the majority of the prescribers to affect quality in the management of febrile illness. Also, majority of the prescribers believed that the level of severity of the illness presented $(87.5 \%)$ and Confidentiality of patients' records $(88.2 \%)$ influenced quality care management of febrile illness respectively. More than half of prescribers $(74.6 \%)$ perceived low participation in National Health Insurance enrolment and proximity to the health facility (69.1\%) influence quality care management. Finally, majority of the prescribers $(65.5 \%)$ perceived superstition to influence the quality of care management as presented in Table 3. 
Table 3: Prescribers' Factors Influencing Quality Care Management of Febrile Illnesses

\begin{tabular}{|l|l|l|}
\hline Variables & $\mathbf{n = 5 8}$ & $\mathbf{\%}$ \\
\hline Superstition & & \\
\hline Yes & 38 & 65.5 \\
\hline No & 20 & 34.5 \\
\hline Confidentiality of patients' records & & \\
\hline Yes & 45 & 88.2 \\
\hline No & 6 & 11.8 \\
\hline Cost of health care & & \\
\hline Yes & 48 & 88.9 \\
\hline No & 6 & 11.1 \\
\hline Geography (Proximity to the hospital) & & \\
\hline Yes & 38 & 69.1 \\
\hline No & 17 & 30.9 \\
\hline Socioeconomic status & & \\
\hline Yes & 49 & 90.7 \\
\hline No & 5 & 9.3 \\
\hline The severity of illness. & & \\
\hline Yes & 49 & 87.5 \\
\hline No & 7 & 12.5 \\
\hline Low participation in health insurance & & \\
\hline Yes & 41 & 74.6 \\
\hline No & 14 & 25.4 \\
\hline
\end{tabular}

Source: Authors Survey, 2020

In univariate and multivariate regression analysis, the results depict that prescribers' factor such as superstition influenced quality care management of febrile illness as detailed in Table 3 For instance, patients who believed in superstition were less likely to receive quality care management of febrile illness as compared with those who did not believe in superstitions $(\mathrm{AOR}=0.50 ; 95 \% \mathrm{CI}=0.03-0.70)$ as shown on Table 4 . 
Table 4: Prescribers' Factors Predicting Quality Care Management of Febrile illnesses

\begin{tabular}{|c|c|c|c|c|}
\hline \multirow{2}{*}{$\begin{array}{l}\text { Model } \\
\text { Variables }\end{array}$} & \multicolumn{2}{|l|}{ Univariate Model } & \multicolumn{2}{|l|}{ Multivariate Model } \\
\hline & $\begin{array}{l}\text { Crude Odd ratio } \\
(95 \% \text { C.I })\end{array}$ & $\begin{array}{l}P \text { - } \\
\text { value }\end{array}$ & $\begin{array}{l}\text { Adjusted Odd ratio } \\
(95 \% \text { CI })\end{array}$ & $\begin{array}{l}\text { P- } \\
\text { value }\end{array}$ \\
\hline \multicolumn{5}{|l|}{ Cost of health care } \\
\hline No (Ref) & 1.00 & - & - & - \\
\hline Yes & $1.70(0.23-2.14)$ & 0.64 & $1.33(0.55-2.06)$ & 0.18 \\
\hline \multicolumn{5}{|l|}{ Superstition } \\
\hline No (Ref) & 1 & - & & \\
\hline Yes & $0.90(0.02-0.44)$ & 0.003* & $0.50(0.03-0.70)$ & 0.02 \\
\hline \multicolumn{5}{|c|}{ Clients proximity to a facility } \\
\hline No (Ref) & 1.00 & - & - & - \\
\hline Yes & $3.97(1.18-13.28)$ & $\mathbf{0 . 0 3}$ & $4.19(0.50-3.4)$ & 0.18 \\
\hline \multicolumn{5}{|c|}{ Low participation in health insurance } \\
\hline No (Ref) & 1.00 & - & - & \\
\hline Yes & $3.47(0.97-12.35)$ & 0.06 & $1.51(0.20-11.30)$ & 0.63 \\
\hline
\end{tabular}

OR: Odds ratio AOR: Adjusted Odds ratio

Source: Authors Survey, 2020

Patients' Socio-Demographic Factors Influencing Quality Care Management of Febrile Illnesses

Univariate and logistic regression analysis were performed to establish patient's sociodemographic factors influencing quality care management of febrile illness. The results depict that, socio-demographic factors such as age of a child and gender influenced quality care management of febrile illness as detailed in Table 5. For instance, children below 1 year were less likely to receive quality care management of febrile illness as compared with those above 3 years $(\mathrm{AOR}=0.05 ; 95 \% \mathrm{CI}=0.08-0.28)$. Also, female children were more likely to receive quality care management of febrile illness as compared with their male counterparts (AOR=1.50; 95\% $\mathrm{CI}=0.03-0.70)$. 
Table 5:.Patient Socio-Demographic Factors Influencing Quality Care Management of Febrile Illnesses

\begin{tabular}{|c|c|c|c|c|}
\hline \multirow{2}{*}{$\begin{array}{l}\text { Model } \\
\text { Variables }\end{array}$} & \multicolumn{2}{|l|}{ Univariate Model } & \multicolumn{2}{|l|}{ Multivariate Model } \\
\hline & $\begin{array}{l}\text { Crude Odd ratio } \\
\text { (OR; 95\% C.I) }\end{array}$ & $\begin{array}{l}\text { P- } \\
\text { value }\end{array}$ & $\begin{array}{l}\text { Adjusted Odd ratio } \\
\text { (AOR; 95\% CI) }\end{array}$ & $\begin{array}{l}P \text { - } \\
\text { value }\end{array}$ \\
\hline \multicolumn{5}{|l|}{ Age of child } \\
\hline Above 3 years (Ref) & 1.00 & - & - & - \\
\hline Below 1 year & $0.70(0.23-2.14)$ & 0.002 & $0.50(0.08-0.28)$ & 0.04 \\
\hline $1-2$ years & $0.81(0.23-2.14)$ & 0.54 & $0.66(0.16-1.84)$ & 0.33 \\
\hline \multicolumn{5}{|l|}{ Gender } \\
\hline Male (Ref) & 1 & - & - & - \\
\hline $\begin{array}{r}\text { Female } \\
\end{array}$ & $1.90(0.02-0.44)$ & 0.004* & $1.50(0.03-0.70)$ & 0.02 \\
\hline \multicolumn{5}{|l|}{ Facility patients are seen } \\
\hline $\begin{array}{ll}\text { Aburaso } & \text { Methodist } \\
\text { Hospital (Ref) } & \end{array}$ & 1 & - & - & - \\
\hline Trinity Hospital & $0.81(0.53-1.24)$ & 0.32 & $0.62(0.43-0.89)$ & 0.22 \\
\hline Millennium Hospital & $0.78(0.55-1.12)$ & 0.18 & $0.61(0.41-0.92)$ & 0.15 \\
\hline $\begin{array}{l}\text { Foase Health } \\
\text { Center }\end{array}$ & $0.54(0.36-0.81)$ & 0.30 & $0.70(0.47-1.02)$ & 0.23 \\
\hline $\begin{array}{ll}\text { Dufie } & \text { Memorial } \\
\text { Clinic } & \end{array}$ & $0.60(0.37-0.98)$ & 0.07 & $0.62(0.43-0.89)$ & 0.09 \\
\hline
\end{tabular}

OR: Odds ratio AOR: Adjusted Odds ratio

Source: Authors Survey, 2020 


\section{DISCUSSION}

The overall assessment of the quality care management in the district was described as good by $60.3 \%$ of the prescribers, while the remaining $39.7 \%$ described it as bad.

The study achieved a response rate of $96 \%$ for the prescribers and $100 \%$ for the client's data collected from the folders. From the demographic characteristics of prescribers in this study, the age distribution was in the range of 23-37years which is an indication of youthfulness of the prescriber's population in the district. This corresponds with general age distribution of the district which also has majority of its members being youthful[18].

Also, a greater number of the prescribers were female $(67.3 \%)$, the possible explanation for this could be as a result of how health staff have been distributed in the district and that is also aligned to the sex distribution of health care professionals in Ghana. Therefore, the majority of the prescribers sampled were nurses (both midwives and general nurses). The educational level of the prescribers was basically first degree and diploma; however, diploma certificates constituted the greater number. As stated earlier, nurses constituted the highest number of prescribers in this study and until recently most of nursing certifications were awarded as diploma, making the nurses with degree few in the system.

Even though there have been varied views on the relationship between work experience and job performance, work experience is generally touted as a function of job performance outcome as the number of years one spends on a particular task is believed to influence his knowledge and skills on that particular task $[19,20,21]$. Our study revealed that prescribers with fewer years of professional practice were $52 \%$ more likely to report poor quality management outcomes of fevers. This could be attributed to inexperience as they may still be learning on the job. Repetitive and routine management of febrile illnesses by prescribers may enable them to sharpen their skills as new and complex situation keeps presenting themselves. This finding is consistent with studies conducted by Lunze et al (22) which revealed that work experience had positive relationship with management outcome.

Again,an average of 3.8 cases of febrile illness is seen by each prescriber daily. This finding contradicts other studies that report fevers to be the most prevalent case seen among children under five years $[6,23]$. This figure may seem smaller; however, it will be depended on the total number of patients seen daily by prescribers in the facilities.

It was also noted that, the gender distribution of childrenfor febrile illnesses in the district is female-dominated and reflects that of the larger district [18]. Infants less than a year also dominated the age of children presenting with febrile illnesses in the district (Table 2). These findings reflected reports from studies conducted elsewhere in Bangladesh [24]. Even though all children appear to be vulnerable when we talk about their resilience to diseases, children under 1year are more susceptible to febrile illnesses and have the worst morbidity and mortality from such conditions.

The treatment outcome of febrile illnesses in general, depends on several factors that are interlinked [25]. The success of most treatment strategies may be linked to the behaviour of both the patient and the prescriber. For instance, no matter how potent a medical prescription may be, unless the user of such medication is committed to following instructions on its dosage. In the same vein, the attitudes and behavior prescribers put up at the clinic may also motivate or demotivate a patient from following instructions. The study examined the various patient factors that are perceived to influence quality care management of febrile illnesses. The majority of prescribers reported that cost of care, severity of illness and economic status play a role in determining quality as far as the management of febrile illnesses is concerned. A third 
of the prescribers mentioned proximity as one of the patient factors they perceive to affect quality. This finding is consistent with a study conducted in Burkina Faso, which reported that patients closer to facilities are likely to return for review compared to those afar, which in effect compromise the treatment of febrile conditions [26,27,25].

Also, factors such as severity of illness, cost of care, and socio-economic status have been reported in several studies to have major influence on an individual's health-seeking behaviors [23,28,29]. For instance, Simanjuntak et al., [30] and Lindblade et al., [31] reported in separate studies that wealthier people are likely to seek early care for their children when compared to people with low-income status.

With regards to other factors related to the prescribers, the client's confidentiality and low insurance coverage and superstition were also mentioned to influence quality care management. The role of socio-cultural beliefs on healthcare treatment outcomes of fevers has been reported in several studies across the globe [32, 26]. However, these cultural beliefs are geographic-specific. Findings from our study are consistent with earlier reports as it revealed that superstition was one of the factors that could influence quality in the management of febrile illnesses. Clinical assessment of quality management cannot be mentioned without considering the client's confidentiality and privacy. It is an essential element as clearly mentioned in the patient charter, a little breach of such element may affect the client-prescriber relationship and in the long run compromise quality. 1-in-3 of the prescribers perceived low insurance coverage as a means which can affect quality care management of febrile illness. This finding corroborates with other studies conducted elsewhere in Ghana [27,33]. They reported that one of the main motivations for seeking care at hospitals against using chemical shops and pharmacies was the existence of health insurance at the former.

Moreover,quality of care has a positive relationship with the age of a child. The likelihood of a child receiving quality care becomes higher as the child advances in age. Children between 0-11 months were less likely to receive quality care management in this study compared with older children between 1-2 years and above 3 years. This could probably be attributed to the fact that these neonates and infants are too young to show signs of discomfort when they are not well. Unlike the relatively older children most of which are able to complain or show visible signs prompting for appropriate treatment. For instance, a report from WHO suggest that risk of deaths for children less than four weeks is 15 times greater than those who have seen their first birthday. A situation which is explained by their weak immunity to deal with new infections compared to the older children [34,35]. It is therefore not surprising that these neonates and infant population in this study constituted a greater number of children presented with febrile illnesses as well as have reduced likelihood of receiving quality care in its management.

Gender was identified as a significant predictor of the quality of care management that a child receives after presenting with febrile illness in this study. Even though all children appear to be vulnerable when we talk about their resilience to diseases, however, the gender role causes a variation in terms of their susceptibility to febrile illness has been reported differently [24]. Whiles some study's findings are consistent with ours, others hold opposing views. For instance, Gold et al.,[36] reported that male children are more susceptible to wheeze, cough, bronchitis than girls. Another study also reports that there is no significant gender difference with respect to febrile illness among children under five [24]. 


\section{Conclusion}

The study concludes that, prescribers' factors such as those who believed in superstition and socio-demographic factors of children such as age and gender influenced quality care management of febrile illnesses in Ghana.

\section{Recommendation}

Health policy makers should promote health education to reduce the negative effects of supersitition in health care management.

\section{References}

1. Heffernan, R., Mostashari, F., Das, D., Karpati, A., Kulidorff, M., \& Weiss, D.Syndromic Surveillance in Public Health Practice, New York City. Emerging Infectious Diseases. 2004. https://doi.org/10.3201/eid1005.030646

2. Hay, A. D., Heron, J., \& Ness, A. The prevalence of symptoms and consultations in pre-school children in the Avon Longitudinal Study of Parents and Children (ALSPAC): a prospective cohort study. Family Practice, 2005a, 22:4, 367-374. https://doi.org/10.1093/fampra/cmi035

3. Alpern, E. R., Stanley, R. M., Gorelick, M. H., Donaldson, A., Knight, S., Teach, S. J., Chamberlain, J. M. Epidemiology of a Pediatric Emergency Medicine Research Network. Pediatric Emergency Care, 2006a, 22:10, 689-699. https://doi.org/10.1097/01.pec.0000236830.39194.c0

4. Massin, M. M., Montesanti, J., Gérard, P., \& Lepage, P. Spectrum and frequency of illness presenting to a pediatric emergency department. Acta Clinica Belgica, 2006a, 61:4, 161-165. https://doi.org/10.1179/acb.2006.027

5. Greenwood, B M, Bojang, K., \& Whitty, C. J. M. Target GAT. Lancet, 2005, 365:1487, 98.

6. Nnedu, O. N., Rimel, B., Terry, C., Jalloh-Vos, H., Baryon, B., \& Bausch, D. G. Syndromic diagnosis of malaria in rural Sierra Leone and proposed additions to the national integrated management of childhood illness guidelines for fever. American Journal of Tropical Medicine and Hygiene, 2010, 82:4, 525-528. https://doi.org/10.4269/ajtmh.2010.09-0188

7. Donabedian, A. The Definition of Quality and Approaches to Its Assessment [= Explorations in Quality Assessment and Monitoring, vol. 1]. Ann Arbor: Health Administration Press, 1980, 8-11.

8. Lohr, K. N., \& Schroeder, S. A. A Strategy for Quality Assurance in Medicare. New England Journal of Medicine.2010. https://doi.org/10.1056/nejm199003083221031 
9. Mosadeghrad, M., A. Obstacles to TQM success in health care systems. International Journal of Health Care Quality Assurance, 2013, 26:2, 147-173. https://doi.org/10.1108/09526861311297352

10. Black, R. E., Morris, S. S., \& Bryce, J. Where and why are 10 million children dying every year? Lancet, 2003, 361:9376, 2226-2234. https://doi.org/10.1016/S01406736(03)13779-8

11. World Health Organisation. (2004). Facts and Figures: Water, Sanitation and Hygiene Links to Health. https://doi.org/10.1136/ip.2004.005405

12. World Health Organization. Guidelines For The Treatment of Malaria - 3rd edition. Www.Who.Int/Malaria. World Health Organization, 2012. https://doi.org/10.1016/0035-9203(91)90261-V

13. WHO. CDS_99.1 World health Organization. Report on infectious Diseases. Removing obstacles to healthy development.pdf. Geneva Switzerland World Health Organization [WHO] 1999. Retrieved from https://www.popline.org/node/284391

14. WHO, \& UNICEF. Handbook IMCI: integrated management of childhood illness. World Health Organization, 2005.

15. Davey, S. World Health Organization report on infectious diseases. Removing obstacles to healthy development, 1999

16. Mosadeghrad, A. M. Factors Affecting Medical Service Quality. Iranian Journal of Public Health, 2014a.

17. Urbaniak, G. C. \& Plous, S. Research Randomizer (Version 4.0) [Computer software]. Retrieved on June 22, 2013, from http://www.randomizer.org

18. Ghana Statistical Service. 2010 Population and Housing Census, District Analytical Report- Kumasi Metropolis. Ghana Statistial Service, 2014 https://doi.org/10.1371/journal.pone.0104053

19. Dokko, G., Wilk, S. L., \& Rothbard, N. P. (2009). Unpacking Prior Experience: How Career History Affects Job Performance. Organization Science, 20(1), 51-68. https://doi.org/10.1287/orsc.1080.0357

20. QuinŃones, M. A., Ford, J. K., \& Teachout, M. S. The relationship Between work experience and Job performance: A conceptual amd Meta-analytic review. Personnel Psychology, 1995. https://doi.org/10.1111/j.1744-6570.1995.tb01785.x

21. Uppal, N., Mishra, S. K., \& Vohra, N. Prior Related Work Experience and Job Performance: Role of personality. International Journal of Selection and Assessment, 2014, 22:1, 39-51. https://doi.org/10.1111/ijsa.12055

22. Lunze, K., Biemba, G., Lawrence, J. J., MacLeod, W. B., Yeboah-Antwi, K., Musokotwane, K., ... Hamer, D. H. Clinical management of children with fever: a cross-sectional study of quality of care in rural Zambia. Bulletin of the World Health Organization. 2017. https://doi.org/10.2471/blt.16.170092 
23. Novignon, J., \& Nonvignon, J. Socioeconomic status and the prevalence of fever in children under age five: Evidence from four sub-Saharan African countries. BMC Research Notes,2012, 5:1. https://doi.org/10.1186/1756-0500-5-380

24. El Arifeen, S., Baqui, A. H., Victora, C. G., Black, R. E., Bryce, J., Hoque, D. M. E., Siddik, A. Sex and socioeconomic differentials in child health in rural Bangladesh: findings from a baseline survey for evaluating Integrated Management of Childhood Illness. Journal of Health, Population, and Nutrition, 2008, 26: 1, 22-35. Retrieved from http://www.ncbi.nlm.nih.gov/pubmed/18637525

25. Müller, O., Traoré, C., Becher, H., \& Kouyaté, B. . Malaria morbidity, treatmentseeking behaviour, and mortality in a cohort of young children in rural Burkina Faso. Tropical Medicine and International Health, 2003. https://doi.org/10.1046/j.13653156.2003.01030.x

26. Adhikari, B., Phommasone, K., Pongvongsa, T., Koummarasy, P., Soundala, X., Henriques, G., Mayxay, M. Treatment-seeking behaviour for febrile illnesses and its implications for malaria control and elimination in Savannakhet Province, Lao PDR (Laos): a mixed method study. BMC Health Services Research, 2019, 19:1, 252. https://doi.org/10.1186/s12913-019-4070-9

27. Ansah, E. K., Gyapong, M., Narh-Bana, S., Bart-Plange, C., \& Whitty, C. J. M. Factors influencing choice of care-seeking for acute fever comparing private chemical shops with health centres and hospitals in Ghana: a study using case-control methodology. Malaria Journal, 2016: 15:1, 290. https://doi.org/10.1186/s12936-016-1351-1

28. Baume, C., Helitzer, D., \& Kachur, S. P. . Patterns of care for childhood malaria in Zambia. Social Science \& Medicine, 2000:5110, 1491-1503. https://doi.org/10.1016/S0277-9536(00)00049-6

29. Molyneux, C. S., Mung'ala-Odera, V., Harpham, T., \& Snow, R. W. Maternal responses to childhood fevers: a comparison of rural and urban residents in coastal Kenya. Tropical Medicine and International Health, 1999, 4:12, 836-845. https://doi.org/10.1046/j.1365-3156.1999.00489.x

30. Simanjuntak, C. H., Punjabi, N. H., Wangsasaputra, F., Nurdin, D., Pulungsih, S. P., Rofig, A., ... Clemens, J. D. Diarrhoea episodes and treatment-seeking behaviour in a slum area of North Jakarta, Indonesia. Journal of Health, Population and Nutrition, 2004, 22:2, 119-129.

31. Lindblade, K. A., Johnson, A. J., Arvelo, W., Zhang, X., Jordan, H. T., Reyes, L., ... Padilla, N. Low usage of government healthcare facilities for acute respiratory infections in guatemala: implications for influenza surveillance. BMC Public Health, 2011a, 11:1, 885. https://doi.org/10.1186/1471-2458-11-885

32. Abubakar, A., Van Baar, A., Fischer, R., Bomu, G., Gona, J. K., \& Newton, C. R. Socio-Cultural Determinants of Health-Seeking Behaviour on the Kenyan Coast: A QualitativeStudy. PLoS ONE, 2013, 8:11, e71998. https://doi.org/10.1371/journal.pone.0071998 
33. Febir, L. G., Asante, K. P., Afari-Asiedu, S., Abokyi, L. N., Kwarteng, A., Ogutu, B., ... Owusu-Agyei, S. . Seeking treatment for uncomplicated malaria: experiences from the Kintampo districts of Ghana. Malaria Journal, 2016: 15:1 108. https://doi.org/10.1186/s12936-016-1151-7

34. Collins, A., Weitkamp, J. H., \& Wynn, J. L. Why are preterm newborns at increased risk of infection? Archives of Disease in Childhood: Fetal and Neonatal Edition, 2018https://doi.org/10.1136/archdischild-2017-313595

35. Cuenca, A. G., Wynn, J. L., Moldawer, L. L., \& Levy, O. Role of innate immunity in neonatal infection. American Journal of Perinatology, 2013. https://doi.org/10.1055/s0032-1333412

36. Gold, D. R., Rotnitzky, A., Damokosh, A. I., Ware, J. H., Speizer, F. E., Ferris, B. G., \& Dockery, D. W. Race and Gender Differences in Respiratory Illness Prevalence and Their Relationship to Environmental Exposures in Children 7 to 14 Years of Age. American Review of Respiratory Disease, 1993, 148:1, 10-18. https://doi.org/10.1164/ajrccm/148.1.10

\section{Acknowledgements}

The authors thank the Management of the Health Facilities where the respondents were selected also supporting us in terms of respondents' availability to generate this data. Again, we are grateful to all the respondents personally for having time with us. The Authors are also grateful to the faculty members of the School of Public Health for their contributions in peer reviewing this paper during the School's seminar series presentations.

\section{Funding}

This study was self-funded by the authors.

\section{Availability of data and materials}

The data that support the findings of this study are available from the corresponding Author upon reasonable request.

\section{Authors' contributions}

AKS led the background development, filed work and analysis of the paper. BJK developed the methodology, was involved in analysis. MAK, ABP, OD and OP were involved in the analysis and write-up. All authors were involved in discussions, conclusion and recommendations put forward by the paper. All authors therefore read and approved the final manuscript.

\section{Ethics approval and consent to participate}

The study was approved by the Committee for Human Research, Populations and Ethics (CHRPE), Kwame Nkrumah University of Science and Technology, Ghana. All the methods were performed in accordance with the relevant guidelines and regulations as understood and approved by CHRPE. Again, all human subjects were provided with written informed consent to participate. Participants therefore gave information out of free will and not under any coerced. 


\section{Consent for publication}

All Authors' have fully consented for this paper to be published.

\section{Competing interests}

The authors declare that they have no competing interests. 